\title{
THE EFFECTS OF ACTIVE AND PASSIVE NECK FLEXION ON UNILATERAL STRAIGHT-LEG-RAISING
}

\section{Craig Smith BSc Physiotherapy*}

\section{INTRODUCTION}

The straight-leg-raise (SLR) test has been previously reviewed with respect to standardising the protocol and highlighting relevant aspects of the literature ${ }^{1}$. SLR tests the integrity of the spinal neural structures, namely the spinal cord, nerve roots and dura mater and serves as an objective diagnostic test for lumbar spinal pathology.

One of the qualifying tests associated with SLR is neck flexion (NF). The application of NF is such that increased tension is applied to these neural structures when performed either with SLR ${ }^{2-8}$ or independently from it ${ }^{9}$, in order to elicit any obstruction to their free movement in the intervertebral canal or foramen.

As the angles that the emergent thoracic and lumbar roots make with the cord are smaller than those made by the cervical nerve roots, there exists greater resistance to cord tension originating cranially rather than caudally ${ }^{10}$. NF provoking sciatic symptoms will therefore imply an increase in tension in the root sheaths and dura mater due to an increase in the bending tensile forces caused at, for example a disc lesion site - known as Hyndman's Sign ${ }^{10,11}$ or Brudzinski's Test ${ }^{3,11,12,13}$.

The bulk of the literature documents that NF be applied passively when added to the SLR test ${ }^{3.4,5,12,14,15}$. Clinically, it proves quite cumbersome to try and maintain the SLR with one hand while passively flexing the neck with the other.

Documentation of active neck flexion (ANF) is minimal and non-specific. Cailliet ${ }^{16}$ and Cyriax ${ }^{17}$ note it to be performed by the patient. Cyriax and Cyriax ${ }^{18}$ demonstrate it pictorially while Hoppenfeld ${ }^{19}$ mentions that in Kernig's Test, the patient forcibly flexes the neck.

None of the authors specify whether NF needs to be applied passively or actively. Surely there can be no difference to the SLR test, as with both methods, tension is applied to the dura and cord and thus transmitted to the lumbosacral roots?

Personal experience and communication with colleagues have brought to light some discrepancy between the amount of SLR available when applying passive neck flexion (PNF) and then ANF on normal subjects (unpublished observations). When ANF was performed, a definite reduction in the resistance of SLR at the end of range (EOR) was observed. The thigh could be flexed a few degrees further on the hip, and the new EOR noted when resistance to the movement was again felt.

No concrete, scientific explanation could be attributed to this phenomenon, and thus it was felt necessary to explore

\section{SUMMARY}

A study was designed to test the effects of passive neck flexion (PNF) as compared with active neck flexion (ANF) on the straight-leg-raise (SLR) test.

Twenty two subjects were measured three times with a goniometer and the difference in range of movement (ROM) was determined by subtracting the SLR recordings obtained by means of PNF from those of ANF. Results demonstrated that neck flexion (NF) performed actively allowed a mean value of $4,13^{\circ}$ more SLR than when performed passively. The implications of these findings are discussed.

OPSOMMING
'n Studie is ontwerp om die uitwerking van passiewe
nekfleksie (PNF) teenoor aktiewe nekfleksie (ANF) op
die reguitbeen-oplig toets (RBO) te ondersoek.
Bogenoemde ondersoeke is op twee-en-twintig per-
sone met behulp van 'n goniometer drie keer gemeet,
en die verskil in bewegingsomvang is bereken deur die
RBO resultate behaal deur middel van PNF van die
van ANF af te trek.
Resultate het gewys dat ANF $4,13^{\circ}$ meer RBO toege-
laat het as die van PNF. Die implikasies van die bevin-
dinge is bespreek.

further by formulating an experiment testing the effects of both ANF and PNF on SLR, in order to determine whether there exists any difference in the amount of SLR range when both are individually and successively superimposed.

If ANF does allow significantly more range of SLR movement than PNF, then its implications for the test would be such that, with more range of motion available, more tension could be exerted upon the nerve roots and thus the quality of symptoms produced could be improved.

\section{METHOD}

\section{SUBJECTS}

Twenty two healthy male (12) and female (10) students with a mean age of 20,8 years $(S D=1,65)$ were tested at the UCT Physiotherapy Department. None of those tested had any known orthopaedic or neurologic dysfunction. Participants were instructed not to begin any new stretching exercises or alter their physical activities during the study period.

\section{GONIOMETRIC VALIDATION}

The reliability and repeatability for the intratester goniometric measuring was evaluated prior to the SLR testing procedure. Firstly, a female's right leg was immobilised in hip flexion (same surface markings described in procedure), and

* Currently studying BSc (Med) (Hons) Sports Science, UCT. This study was submitted in partial fulfillment of the requirements for BSC Physiotherapy at the University of Cape Town). 
seven measurements were taken by the tester with the same goniometer. The same leg was then immobilised at a fixed angle in the SLR position using the pulley system to be described, and a further seven measurements were taken as before. These measurements were then analysed for variability (coefficient of variation) to determine intratester reliability and repeatability and are reported in the results section.

\section{INSTRUMENTATION}

An overhead pulley system was used to maintain the passive SLR on each subject's right leg. The range of movement (ROM) was measured with a plastic long arm goniometer, which was found to be of high reliability when compared with the tape measure and flexometer for recording $\operatorname{SLR}^{20}$. A pressure transducer (calibrated in millimetres mercury [mmHG]) was used to indicate the EOR by measuring the resistance of the hamstrings and posterior thigh structures. This method was employed as subjective estimates of EOR would have varied considerably due to different pain threshold levels between subjects.

A plasterzote knee backslab was applied to each right leg with a crepe bandage in order to prevent knee flexion. A sling was placed beneath each subjects' right heel, and provided the point of attachment for the pulley's rope, as well as keeping the pressure transducer in place. The rope was then passed through a hook above the subject's right hip so that its force was exerted at about $90^{\circ}$ to the leg when SLR was performed.

\section{PROCEDURE}

In order to measure the angles of SLR, the following anatomical landmarks were delineated:-

a) the greater trochanter

b) a point on the line connecting the greater trochanter and the lateral femoral condyle

c) a point on the horizontal line from the greater trochanter to the mid axilla.

After being marked, each subject was then positioned on the plinth in supine and the backslab applied. The pressure transducer was preset for each measurement at $40 \mathrm{mmHg}$, and placed under the heel within the sling. The rope was connected to the sling and passed through the hook, and the free end given to the subject. They were then instructed to relax their hamstring muscles, and not to resist or assist the SLR in any way.

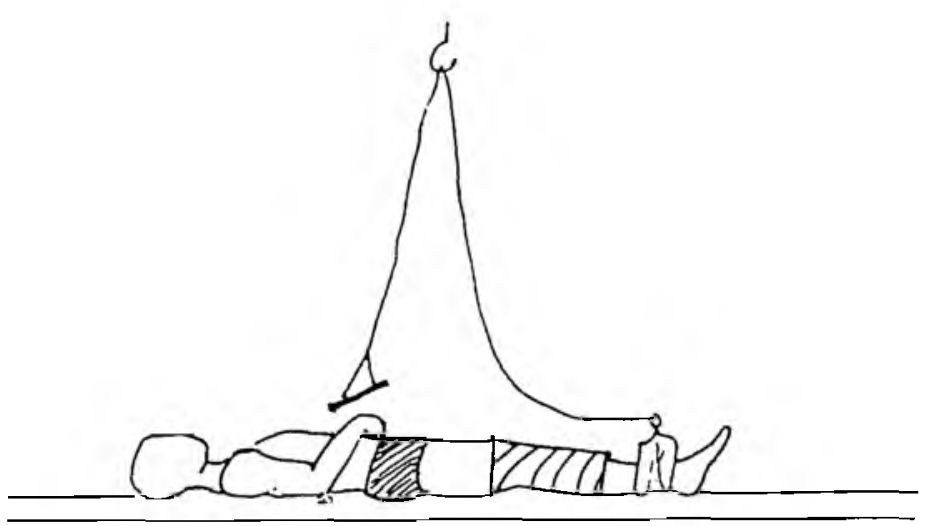

Fioure 1: SLR starting position showing the knee backslab, the pulley and the sling
Each subject's right leg was then raised by the tester, (with attention to the SLR biomechanical detail as described before $^{1}$ ) until the pressure gauge value read $120 \mathrm{mmHg}$. At this stage each subject was asked to hold the opposite end of the rope with both hands while keeping their elbows on the plinth. This maintained the SLR position and enabled the tester to read the pressure values and measure the SLR range with the goniometer.

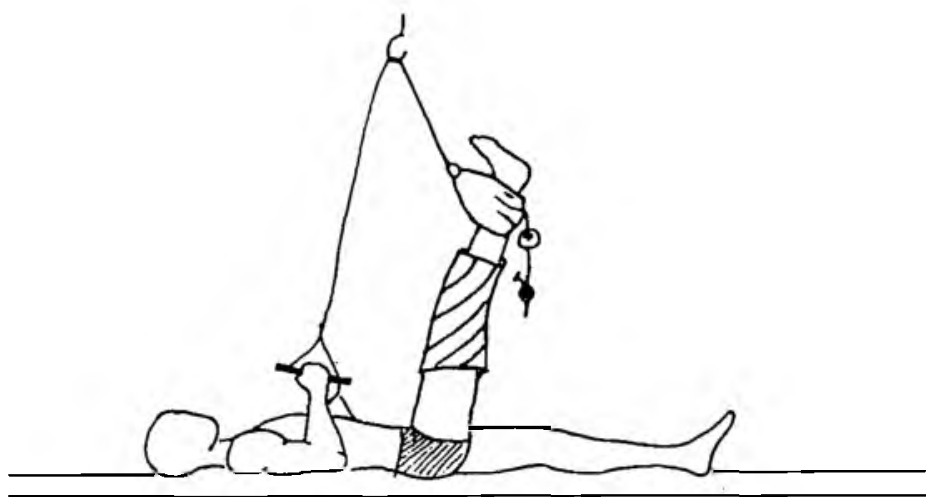

Figure 2: The subject stabilising the leg once passive SLR has been performed

PNF was then applied, and the gauge consulted to see if any changes in pressure had occurred. If so, these were recorded. The head was then lowered, and the gauge rechecked to ensure it read $120 \mathrm{mmHg}$. The subject was then instructed to actively lift his head himself, approximating his chin to his chest while keeping his shoulders on the plinth. The pressure gauge was again checked and the changes (decreases) in values were then recorded. With the neck still flexed, the leg was then raised further by the tester until the gauge read $120 \mathrm{mmHg}$ again. This new range of SLR was then measured and recorded. Only then was the subject told to lower his head and leg to the plinth.

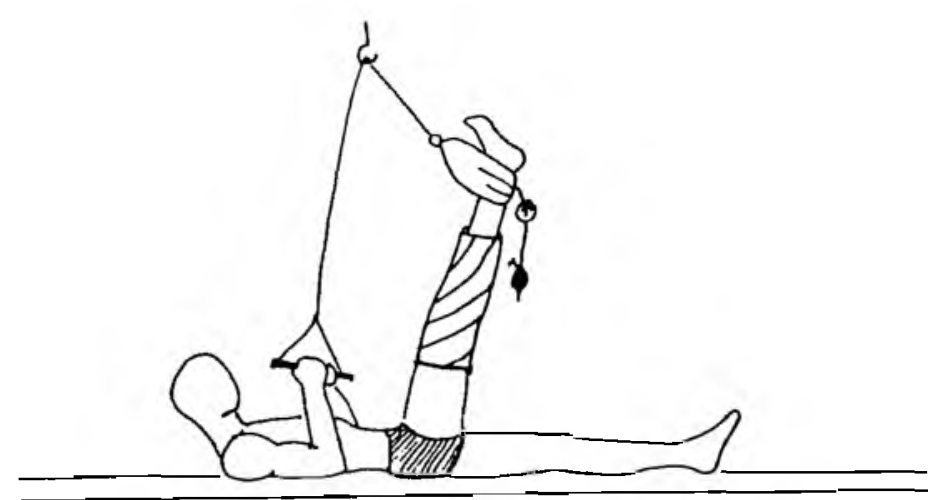

Figure 3: ANF superimposed on passive SLR.

This procedure was performed three times on each subject, with a one minute rest in between.

The data was analysed for statistical significance using the student's t-test.

\section{RESULTS}

The coefficients of variation for the goniometric measurements of hip flexion and SLR were $1,5 \%$ and $1,3 \%$ respectively. Values less than $10 \%$ are regarded as acceptable, and 
thus the above results suggest highly acceptable intratester reliability and repeatability, with the possibility of goniometric error being low.

There were no changes in pressure readings when PNF was applied to SLR, while with ANF, the readings decreased by a mean value of $6,5 \mathrm{mmHg}$.

\begin{tabular}{|c|c|c|c|c|c|c|}
\hline $\begin{array}{c}\text { SLR } \\
\text { Procedure no. }\end{array}$ & $\mathrm{n}$ & mean & s e m & $\mathrm{t}$-value & DF & P \\
\hline 1 & 22 & 3.91 & 0.48 & 8.07 & 21 & 0.001 \\
\hline 2 & 22 & 3.91 & 0.46 & 8.41 & 21 & 0.001 \\
\hline 3 & 22 & 4.59 & 0.46 & 9.88 & 21 & 0.001 \\
\hline Average & 22 & 4.13 & 0.47 & 8.79 & 21 & 0.001 \\
\hline
\end{tabular}

TABLE: Mean, standard error mean, t-value, degrees of freedom and probability for the increased range in degrees of SLR with ANF

From the table, it can be seen that the angle of SLR was greater with ANF than with PNF during all three procedures. These values correspond to a significant average mean increase of $4.13^{\circ}(p<0.001)$. These increases were calculated by subtracting the SLR ranges with PNF from those with ANF.

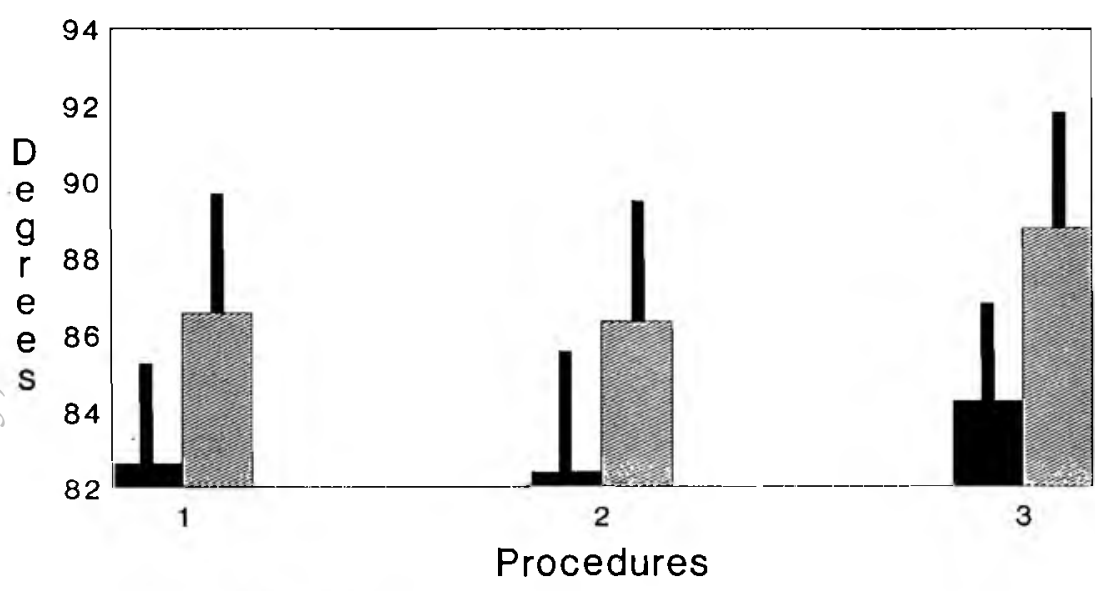

Initial SLR 展 Final SLR with ANF

Figure 4: Mean and sem values for initial and final SLR measurements

Figure 4 depicts the relationships between the three procedures' mean initial and final measurements. For procedures one and two, both initial and final readings correlate very closely, varying by only $0,24^{\circ}$ and $0,23^{\circ}$ respectively. The third procedure's readings were greater than those of the first two, and varied from their combined mean average for the initial and final readings by $1,73^{\circ}$ and $2,31^{\circ}$.

These increases can be attributed to the possible stretching and relaxing of the hamstring muscles by the time the third measurements were taken. This might have indicated that some form of stretching exercises should have been performed before measurements were taken, to minimise the hamstrings from stretching further during the three procedures.

\section{DISCUSSION}

The results of this study clearly indicate that more SLR was achieved with ANF than with PNF. Analytical comparisons showed a statistically significant difference between the two ( $p<0,001)$, and it is thus evident that the method of applying NF does affect the range of SLR.

The intratester reliability and repeatability of the goniometric measurements were well supported by the coefficients of variation for hip flexion $(1,5 \%)$ and for SLR in the sling $(1,3 \%)$, and compare with reports by Hsieh et $\mathrm{al}^{20}$ that the goniometer is of high intrasession and intersession reliability and repeatability.

What then are the causes for ANF allowing more SLR then PNF? The most likely answer to this question involves the abdominal muscles. When in supine, flexing the neck is an action against gravity, and is performed by the two sternocleidomastoid muscles working in unison. With this movement being performed, overflow to the abdominal muscles occurs. This can be demonstrated by lying on your back and placing your hands on your abdomen. When you lift your head off the surface, the abdominals are immediately felt to contract tightly. They originate from the sternum and lower ribs and insert into the iliac crests, the superior pubic rami and the symphysis pubis. Thus, when they contract, tension results between the two points of fixation, and if either point is not stabilised, movement can occur ${ }^{21}$. In this case, the chest wall and sternum are rigid, and thus the movement takes place at the pelvis. The abdominal insertions will cause the anterior pelvis to rotate forwards and upwards, and because the back extensors which insert into the posterior pelvis are relaxed, it will rotate backwards and downwards. This pelvic rotation thus relaxes the tension in the hamstring muscles and posterior thigh structures, because of their insertions to the postero-inferior aspect of the pelvis.

Posterior pelvic rotation occurring with SLR begins as early as $10^{\circ}$ of hip flexion ${ }^{23}$, and can be referred to as the pelvifemoral motion ${ }^{22-25}$. Results have shown that at a maximum SLR of $87,3^{\circ}$, contributing factors were increases of $32,1^{\circ}$ in the pelvis/horizontal angle, and $55,2^{\circ}$ in the SLR/pelvis angle $^{23}$. Thus, if this much pelvic rotation were occurring just with SLR motion, it would indicate that the pelvis is not completely stabilised during SLR, and applying the force of the abdominals to it during ANF, could result in further rotational movement.

This pelvic rotation thus exerts its effects on the SLR leg through the pelvifemoral motion. The increased posterior pelvic rotation at the end of SLR slightly relieves the tension in the hamstrings, and thus more range of SLR is available, until the hamstrings are once again tight and resisting the movement.

In this study, the increase in pelvic rotation was found to be $4,13^{\circ}$, (from $83,10^{\circ}$ to $87,23^{\circ}$ ) and relates directly to the hypothesis that more SLR can be achieved when ANF rather than PNF is superimposed.

\section{CLINICAL IMPLICATIONS}

If this is then the case, how do these findings relate to the clinical environment.

Firstly, applying NF to the SLR $\hat{R}_{\text {test }}$ increases the tension in the dura mater and the lumbosacral nerve roots. Whether applied passively or actively, this resultant tension is achieved.

However, ANF applied to SLR adds a few more degrees to the SLR angle. This should then apply further tension to 
the sciatic nerve and its roots, making the test more specific. As previously documented ${ }^{1}$, the root tension and movement with SLR is considered to increase only up to $70^{\circ}$, after which it becomes sluggish and ceases at $90^{\circ 15,30,37}$. It would then seem that ANF used with SLR might only be effective if the end of the SLR angle is anywhere less than or equal to roughly $70^{\circ}$.

If SLR is limited by back and/or leg pain comparable to sciatic nerve involvement, then the purpose of the NF qualifying test is only to reproduce or enhance this pain. No further range of SLR is required (as this would only exacerbate the patient's pain and make it quite unbearable) and thus ANF or PNF can be used.

Because we know that SLR also causes lumbo-pelvic movement, irritable facet or sacroiliac joints can also produce comparable back pain ${ }^{1}$. Therefore, NF could be used as a differentiating test for neural or articular structure involvement ${ }^{1}$. Pain on further SLR reproduced with ANF can either be due to stretching of the dura mater or movement of the irritable lumbosacral joints, due to pelvic rotation caused by the abdominals. If PNF is then applied and the pain enhanced, then this can only be attributed to the fact that the dura and nerve roots' mobility are being painfully impaired, for there does not exist any anatomical means by which PNF can exert any effect on the sacroiliac or facet joints, or even be thought of to be a cause for pelvic movement.

If PNF does not cause an increase in painful symptoms, then the cause can most likely be attributed to the irritable lumbo-pelvic joints which are being mobilised with SLR and ANF, or neural structures unaffected by NF (e.g. disc prolapse situated inferomedially to the nerve root and dura mater $^{28}$ ).

If ANF exerts an effect on the pelvis and indirectly on the hamstrings, are there any other structures which might also be affected?

The isometric contraction of the abdominal musculature with ANF helps to decrease intradiscal pressures ${ }^{29}$ by increasing intra-abdominal pressure. The increase in intra-abdominal pressure together with the splinting effect of the abdominal muscles, reduces the pressure on the discs. Further studies would be needed to determine if there exists any abating of discal symptoms with the decrease in intradiscal pressure when ANF is applied.

Fisk $^{30,31}$, referring to hamstring tightness and SLR, notes that "limited SLR by the hamstring muscles can be improved with manipulation of the lumbar spine, resulting in either alteration of the gamma inflow to the muscle spindles allowing lengthening of the hamstrings, or sacro-iliac joint mobilisation". That ANF might exert an effect on the hamstrings by also altering the gamma inflow to the muscle spindles or any other neurological pathway can only be seen as speculation, and further insight and experimentation would be needed to determine if any relationship does exist.

\section{RECOMMENDATIONS}

Having analysed and tabulated the results for the twentytwo normal subjects who took part in this experiment, it can be seen that it can only be regarded as a pilot study. The study itself needs to include a larger number of candidates, spanning a wider age group; $12-16$ years and $35-55$ years.

More care also needs to be taken to attempt to control the interfering variables which might have affected the results. These were;

1. movement of the skin where the bodymarkings were delineated, such that they were no longer over the bony landmarks being represented, when SLR measurements were taken

2. leg weight differences between subjects, exerting varied forces on the pressure transducer

3. the position of the hook of the pulley above the right hip. Visual estimates of the point above the right hip were used, and varied positions could have caused different angles of pull of the rope on the SLR leg.

Further research involving $A N F$, pelvic rotation and SLR would be beneficial in helping to understand this phenomenon.

1. Tests performed in the clinical environment involving subjects with back symptoms, to determine whether ANF and PNF can actually be used in a differentiating role, for patients who exhibit articular and neural symptoms.

2. A study to determine how much more pelvic rotation actually does occur when ANF is added to full SLR.

3. ANF tested on passive and active SLR.

4. Lastly, experimentation to determine the neurological effects of ANF on hamstring muscle spindle control.

\section{CONCLUSION}

The angle of SLR with ANF was definitely more than the angle with PNF. This bears important clinical relevance with regard to how NF is performed, as well as qualifying the signs produced with SLR.

Emphasis is not placed on demanding the sole use of ANF, but with the clinician's discretion, it can be useful in:-

i) applying more tension to the nerve roots, and

ii) differentiating between neural and articular low back pain causes.

\section{REFERENCES}

1. Smith CA. Analytical Literature Review of the passive Straight-Leg-Raise Test. South African Joumal of Physiotherapy 1989;45(4):104-107.

2. Cyriax J. Dural Pain. Lancet 1978;1:919-921.

3. Grieve GP. Mobilisation of the spine. 4th ed. Edinburgh : Churchill Livingstone, 1976:46-48.

4. Maitland GD. Vertebral Manipulation. 5th ed London : Butterworth, 1986:67-71.

5. Breig A, Troup JDG. Biomechanical considerations in the straight-leg raising test. Spine 1979;4():242-250.

6. Edgelow PI. Physical examination of the lumbosacral complex. Phys Ther 1979;59(8):974-977.

7. Breig A, Marrions O. Biomechanics of the lumbosacral nerve roots. Acto Radiol 196;1:1141-1160.

8. Reid JD. Flexion extension movements of the head. J Neurol Neurosurg Psychiatry 1960;23(3)214-221.

9. Edgar MA, Park WM. Induced pain patterns on passive straight-leg-raising in lower lumbar disc protrusions. J Bone Joint Surg 1974;56B:658-667.

10. Breig A. Adverse Mechanical Tension in the Central Nenous System Stockholm : Almqvist and Wiksell, 1978:14-15, 38-43, 152-170.

11. Urban LM. SLR test : a review. In : Grieve GP, ed. Modem Manual Therapy of the Vertebral Column. Edinburgh: Churchill Livingstone, 1986:567-575.

12. Brody IA, Wilkins RH. The signs of Kernig and Brudzinsky. Arch Newrol 1969;21:215-216.

13. Wilkins RM, Brody IA. Lasegue's Sign. Arch Neurol 1969;21:219-220.

14. Scham S, Taylor T. Tension signs in the lumbar disc prolapse. Clin Orthop 1971:75:195-204.

15. Jull GA. Examination of the lumbar spine. In: Grieve GP, ed. Modem 
Manual Therapy of the Vertebral Column. Edinburgh: Churchill Livingstone, 1986:556-557.

16. Cailliet R. Low Back Pain. 3rd Ed. Philadelphia : F A Davis Company, 1981; 152-158, 178-180.

17. Cyriax JH. Texbook of Orthopaedic Medicine Vol 17 th ed. London : Balliere Tindall, 1982 : 378-389, 414-419.

18. Cyriax JH, Cyriax PJ. Ilustrated Manual of Orthopaedic Medicine. London: Butterworths, 1983:188.

19. Hoppenfeld S. Physical Examination of the Spine and Extremities. New York : Appleton Century-Crofts, 1976:256-259.

20. Hsieh C, Walker JM, Gillis K. Straight-leg-raising test: Comparison of three instruments. Phys Ther 1983;63(9):1429-1433.

21. Galley PM, Forster AL. Human Movement. Edinburgh: Churchill Livingstone, 1982:32.

22. Bohannon RW. Cinematographic analysis of the passive st raight-leg-raising test for hamstring muscle length. Phys Ther 1982;62(9):1269-1274.

23. Bohannon RW, Gajdosik RL, Le Veau BF. Cont ribution of pelvic and lower limb motion to increases in the angle of passive straight-leg-raising. Phys Ther 1985;65(4):474-476.

24. Gajdosik RL, Le Veau BF, Bohannon RW. Effects of ankle dorsiflexion on active and passive unilateral straight-leg-raising. Phys Ther 1985;65(10):1478-1482.

25. Bohannon RW, Gajdosik RL, Le Veau RF. Relationship of pelvic and thigh motions during unilateral and bilateral hip flexion. Phys Ther 1985;65(10):1501-1504.

26. Charnley J. Orthopaedic signs in the diagnosis of low back pain. Lancet 1951;1:186-189.

27. Fahmi WM. Observations on straight-leg-raising with special reference to nerve root adhesions. Can J Surg 1966;9(1):44-48.

28. Kessler RM. Acute symptomatic disc prolapse: Clinical manifestations and therapeutic considerations. Phys Ther 1979;59(8):978-987.

29. Jensen GM. Biomechanics of the lumbar intervertebral disc: A Review. Phys Ther 1980;60(6):765-773.

30. Fisk JW. The passive hamstring test: Clinical evaluation. $N A M e d J$ 1979;89(631):209-211.

31. Fisk JW. The straight-leg-raising test: its relevance to possible disc pathology. $N$ Z Med J 1975;81(541):557-560. As

\section{CLASSIFIED ADVERTISEMENTS}

\section{URGENTLY REQUIRED}

Part-time Physiotherapist experienced in in-patient orthopaedics (mainly trauma) to assist in clinical supervision/teaching of third and fourth-year physiotherapy students.

Hours: 3 mornings per week, 08:00 12:00

University holidays free.

Salary: 3/8 of appropriate notch of Junior Lecturer's scale, according to experience.

Starting date: 1 February 1990, or as soon as possible thereafter.

APPLICATIONS should be submitted to the following:

Miss S Irwin-Carruthers, Department of Physiotherapy

P O Box 63, Tygerberg 7505 .

\section{PRETORIA}

Full time post available in orthopaedic practice. Conditions treated include joint replacements and rehabilitation following specific shoulder surgery

CONTACT: Carol Castleman, (012) 343-1298 (w), 57-6373 (h)

ELIM HOSPITAL, Northern Transvaal.

Physiotherapist urgently required for hospital and community work (TPA post).

CONTACT: Dr Jacques (Medical Superintendent)

P O Box 12, Elim Hospital, 0960, or telephone (01552) 611, extension 126 or 216 .

\section{PAARL}

A community based project in Mbekweni (Paarl) would like to employ a Physiotherapist on a sessional basis to work with stroke patients.

The work will involve assessment of patients as well as the training and supervision of a community based health worker. Experience in adult neurology is an advantage but not essential. Ability to speak Afrikaans and/or Xhosa will also be an advantage.

Transport will be available from Cape Town.

PHONE: Ian MacKenzie at (021) 47-7863 (oh) or 47-9073 (ah), or apply to P O Box 234, Salt River 7925

\section{CLASSIFIED ADVERTISEMENTS}

\section{CAPE TOWN}

Full time physiotherapist required for a private practice in central Cape Town.

Work involves cardio-thoracic intensive care and in- and out-chest patients.

Starting April - July 1990.

PLEASE CONTACT: Mrs S Pollock, page (021) 61-634, or 531-8619 (ah).

\section{PRACTICE AVAILABLE IN ESSEX}

Busy Essex Practice for sale. Fully equipped including receptionist and staff.

Close to local schools; bus link, shops and railway.

Referrals from local GP's and Orthopaedic Specialists in the area. Well established over the past six years, currently seeing a $100+$ patients per week and enjoying an excellent variety of spinal and peripheral/orthopaedic conditions.

London within 55 minutes by train or car.

WRITE TO: LRT Brown, 49 High Road, Rayleigh, Essex SS6 7SE, or telephone 0268-777641.

\section{ASSOCIATION FOR CHILDBIRTH AND PARENTHOOD}

5th Workshop for professionals who deal in childbirth and parent-

hood.

Date: Saturday 24 March 1990

Time: $\quad$ 10h30 15h 30

Venue: University of Pietermaritzburg

Topics: "Teenage Pregnancy"

"Open Adoption"

Fee: (includes Lunch)

Non-members R35,00

ACP Members R25,00

Students R15,00

To book contact: Doreen O'Neill, P O Box 22491, Glenashley 4022 Tel: (031) 52-5128.

\section{NEW PRACTICE IN HILLBROW}

Arie Michaeli wishes to inform his colleagues that as from 1st January, 1990 he will be practicing privately at:

416 Tower Hill, Kotze Street, Hillbrow, Johannesburg. Office hours (011) 724-2359, after hours: 643-6473.

\section{NOTICE OF MEETING}

The Neuro-rehabilitation Group will next meet on Saturday $17 \mathrm{Fe}$ bruary 1990, in the Physiotherapy Department, Johannesburg Hospital, at 9.00 am.

Subjects for discussion:

(1) Cognitive changes in head injuries

(2) Rhizotomies.

\section{Physiotherapist}

\section{SETTLERS HOSPITAL, GRAHAMSTOWN}

- Dutles: Administering of Physiotherapy to in-/outpatients at the abovementioned hospital.

Registration with the S.A. Medical and Dental Council as a Physiotherapist is essential.

- Salary: A salary to a maximum of R25 371 per annum may be granted according to qualifications and experience.

Application must be made on the prescribed form (Z.83, obtainable from any government office) and forwarded to the Medical Superintendent, Settlers Hospital, Private Bag 1007, Grahamstown 6140.

Closing date: 28 February 1990. 